\title{
Nontumoral Portal Vein Thrombosis: A Challenging Consequence of Liver Cirrhosis
}

\author{
Manus Rugivarodom and Phunchai Charatcharoenwitthaya*
}

Division of Gastroenterology, Department of Medicine, Faculty of Medicine, Siriraj Hospital, Mahidol University, Bangkok, Thailand

\begin{abstract}
Nontumoral portal vein thrombosis (PVT) is an increasingly recognized complication in patients with cirrhosis. Substantial evidence shows that portal flow stasis, complex thrombophilic disorders, and exogenous factors leading to endothelial dysfunction have emerged as key factors in the pathogenesis of PVT. The contribution of PVT to hepatic decompensation and mortality in cirrhosis is debatable; however, the presence of an advanced PVT increases operative complexity and decreases survival after transplantation. The therapeutic decision for PVT is often determined by the duration and extent of thrombosis, the presence of symptoms, and liver transplant eligibility. Evidence from several cohorts has demonstrated that anticoagulation treatment with vitamin $\mathrm{K}$ antagonist or low molecular weight heparin can achieve recanalization of the portal vein, which is associated with a reduction in portal hypertension-related events and improved survival in cirrhotic patients with PVT. Consequently, interest in direct oral anticoagulants for PVT is increasing, but clinical data in cirrhosis are limited. Although the most feared consequence of anticoagulation is bleeding, most studies indicate that anticoagulation therapy for PVT in cirrhosis appears relatively safe. Interestingly, the data showed that transjugular intrahepatic portosystemic shunt represents an effective adjunctive therapy for PVT in cirrhotic patients with symptomatic portal hypertension if anticoagulation is ineffective. Insufficient evidence regarding the optimal timing, modality, and duration of therapy makes nontumoral PVT a challenging consequence of cirrhosis. In this review, we summarize the current literature and provide a potential algorithm for the management of PVT in patients with cirrhosis.
\end{abstract}

Citation of this article: Rugivarodom M, Charatcharoenwitthaya P. Nontumoral portal vein thrombosis: A challenging consequence of liver cirrhosis. J Clin Transl Hepatol 2020;8(4):432-444. doi: 10.14218/JCTH.2020.00067.

Keywords: Portal vein thrombosis; Liver cirrhosis; Clinical course; Anticoagulation; Transjugular intrahepatic portosystemic shunt.

Abbreviations: AASLD, American Association for the Study of Liver Diseases; $\mathrm{CI}_{\text {, }}$ confidence interval; CT, computed tomography; CTP, Child-Turcotte-Pugh; DOAC, direct oral anticoagulant; EASL, European Association for the Study of the Liver; $\mathrm{HCC}$, hepatocellular carcinoma; HR, hazard ratio; LMWH, low molecular weight heparin; MELD, model for end-stage liver disease; MRI, magnetic resonance imaging; MTHFR, methylene tetrahydrofolate reductase; $O D$, odds ratio; PVT, portal vein thrombosis; SMV, superior mesenteric vein; TEG, thromboelastography; TIPS, transjugular intrahepatic portosystemic shunt; VKA, vitamin $\mathrm{K}$ antagonist. Received: 16 July 2020; Revised: 27 September 2020; Accepted: 18 October 2020 *Correspondence to: Phunchai Charatcharoenwitthaya, Division of Gastroenterology, Department of Medicine, Faculty of Medicine, Siriraj Hospital, Mahidol University, Wang-Lang Road, Bangkoknoi, Bangkok 10700, Thailand. Tel: +662419-7282, Fax: +662-411-5013, E-mail: phunchai@yahoo.com

\section{Introduction}

Portal vein thrombosis (PVT) is characterized by thrombus formation within the trunk of the portal vein or its main branches, which may extend to the splenic or superior mesenteric veins (SMVs). ${ }^{1-3}$ It is further classified according to site, degree, extent, and functional relevance of the thrombosis, as well as the presence of underlying liver disease (Supplementary Table 1). ${ }^{4-12}$ Recently, an "anatomico-functional classification system" that incorporates anatomic descriptors, timing of the thrombosis, and the relationship to clinical sequelae, was proposed (Supplementary Fig. 1). ${ }^{12}$ PVT represents a well-known complication during the natural history of patients with liver cirrhosis. Evidence is accumulating that the rebalanced hemostasis system in cirrhosis is prone to hypercoagulability. ${ }^{13}$ In patients with cirrhosis, the development of PVT is a milestone in the progression of advanced liver disease and increases the risk of death. ${ }^{14}$ The complex hemostatic state in chronic liver disease makes it challenging to manage PVT in cirrhotic patients. The international guidelines provide brief recommendations on many aspects of treating PVT. $2,3,11,15$ This review aims to address the essential knowledge for the management of PVT in patients with cirrhosis.

\section{Epidemiology}

The prevalence of nontumoral PVT increases with severity of the liver disease, being approximately $1 \%$ in patients with compensated cirrhosis and $8-25 \%$ in candidates for liver transplantation. ${ }^{16-21}$ Different types of diagnostic approaches used in various studies may be responsible for heterogeneity in the reported prevalence, ranging from $0.6-16 \%$ using angiography or surgery to $10-25 \%$ using ultrasonography. ${ }^{22}$

The incidence of nontumoral PVT in liver cirrhosis has been reported in a limited number of studies. Among patients with virus-related cirrhosis, the cumulative incidence of de novo PVT was $12.8 \%, 20 \%$, and $38.7 \%$ at 1,5 , and $8-10$ years, respectively. ${ }^{20} \mathrm{~A}$ longitudinal assessment of PVT in 1,243 cirrhotic patients with Doppler ultrasonography revealed that overall 1-, 3- and 5-year cumulative incidence rates of PVT were $4.6 \%, 8.2 \%$, and $10.7 \%$, respectively. ${ }^{23}$ The incidence of nontumoral PVT in liver transplant candidates was reported as $2.1-23.3 \%$ per year. ${ }^{5,24-30}$ Part of these differences may be due to different transplant policies. Nearly half of the nontumoral PVT was discovered at the time of liver transplantation. ${ }^{31}$ Of these, $58.3 \%$ was partial, and $41.7 \%$ was complete PVT. ${ }^{24}$ Recently, a multicenter prospective study PRO-LIVER (PVT Relevance On Liver cirrhosis: Italian Venous thrombotic Events Registry) involving 753 cirrhotic patients assessed 
with Doppler ultrasound reported the incidence rate of PVT as 6.05 per 100 patient-years. ${ }^{32}$ The incidence of PVT was higher in patients with a history of PVT, indicating that PVT per se carries a risk for recurrence.

\section{Pathophysiology}

In general, the predisposing factors of PVT are categorized into local and systemic factors. ${ }^{33}$ The portal venous system in cirrhosis represents a local environmental factor particularly prone to thrombus formation by reduced blood flow from portal hypertension and the inflammatory milieu secondary to hepatic injury and gut translocation of bacteria or their by-products. A wide variety of systemic factors are described, including inherited and acquired thrombophilic disorder, extra-abdominal cancer, hormonal therapy, and autoimmune disorder. ${ }^{34}$ The risk of a thrombotic event is substantial with the presence of any components of Virchow's triad, including venous stasis, hypercoagulability, and endothelial dysfunction. The role of the three components contributing to PVT development has been extensively investigated in cirrhosis (Fig. 1).

Portal venous stasis secondary to the liver architectural derangement and the splanchnic vasodilatation seems to be the most crucial local factor responsible for the development of PVT in the setting of cirrhosis. ${ }^{35}$ Reduced portal flow velocity was identified as an independent factor associated with the development of PVT. ${ }^{18}$ This finding was supported by the evidence that a portal flow velocity of less than $15 \mathrm{~cm} / \mathrm{s}$ at Doppler ultrasonography is the most important risk factor for developing PVT in patients with cirrhosis. ${ }^{36}$ The flow in the portal vein becomes further decreased by a "steal effect" due to a spontaneous portosystemic shunt. The presence of collateral vessels, with flow volume of more than 400 $\mathrm{mL} / \mathrm{min}$ and a flow velocity of more than $10 \mathrm{~cm} / \mathrm{s}$, was found to be a significant predictive factor for the occurrence of PVT in cirrhosis. ${ }^{20}$

The decreased levels of most coagulation factors, except factor VIII and von Willebrand factor, are characteristic hallmarks of hemostasis in cirrhosis. ${ }^{37,38}$ Also, a parallel reduction of natural anticoagulant factors, such as protein $\mathrm{C}$ and $\mathrm{S}$, is observed. However, the contribution of hemostatic alterations to PVT development is challenging to evaluate because these may be due to co-existing liver dysfunction in advanced cirrhosis, rather than a primary disturbance. ${ }^{15}$ The conventional coagulation assays reflect only the clot formation time in a plasma environment. The tests do not include thrombomodulin measurement; therefore, they are unsuitable for investigating acquired deficiency of both pro- and anticoagulants, as occurs in cirrhotic patients. ${ }^{13}$ Thromboelastography (TEG), known as the viscoelastic test, can offer a global assessment of the hemostatic pathways. ${ }^{39}$ This whole blood test allows a dynamic assessment of clot formation and dissolution that might help assess the relative contribution of the coagulation components to overall clot formation and dissolution in cirrhotic patients. ${ }^{39}$ It has been solidly demonstrated to be useful in guiding transfusion for gastrointestinal bleeding and high-risk liver invasive procedures. ${ }^{40,41}$ Few studies use TEG as the reference method for the function evaluation of multiple clotting components in patients with PVT. ${ }^{42-44} \mathrm{~A}$ recent study evaluated thromboelastographic parameters among cirrhotic patients with variceal bleeding. ${ }^{44}$ TEG showed a shortening of initial fibrin formation time in cirrhotic patients with PVT, indicating activation of plasma clotting

\section{Local Predisposing Factors}

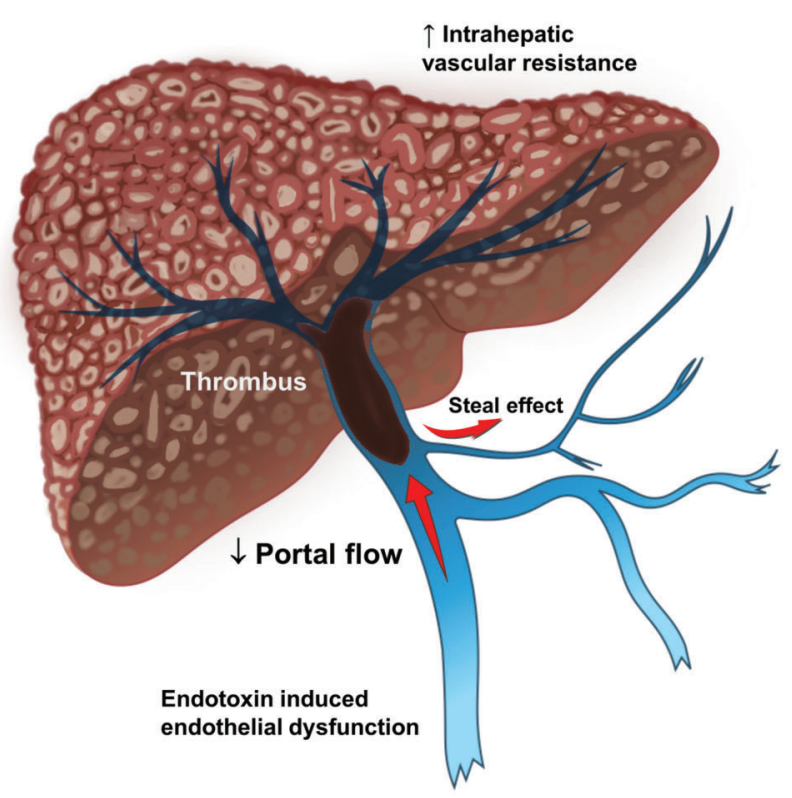

\section{Systemic Predisposing Factors}

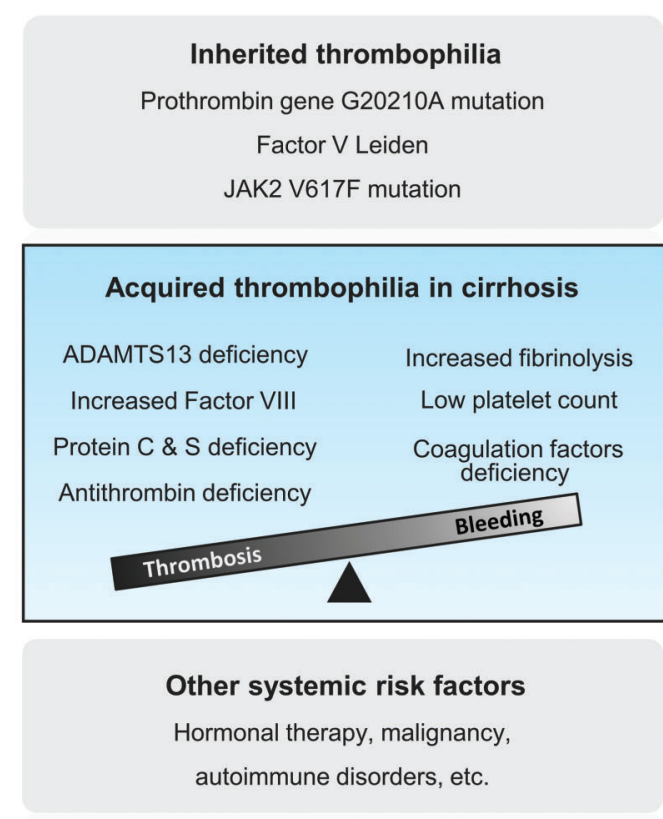

Fig. 1. Pathogenesis of nontumoral portal vein thrombosis (PVT) in liver cirrhosis. Both local and systemic factors have been involved in the development of PVT in patients with cirrhosis. The portal venous system in cirrhosis represents a local predisposing factor prone to thrombus formation by reduced portal blood flow from portal hypertension and increased intrahepatic vascular resistance with the inflammatory milieu secondary to gut-derived bacterial lipopolysaccharide. Cirrhotics have been traditionally considered prone to bleeding due to thrombocytopenia, defects of procoagulant factors, and fibrinolysis. However, there is growing evidence that hypercoagulability is an important part of the hematological spectrum in cirrhosis. The unstable coagulation balance can be tiled toward thrombosis if any acute insult ensues. 
factors and inhibiting circulating inhibitors in this population. However, further studies are needed to define the appropriate TEG-guided approach to managing PVT in cirrhotic patients.

An early study revealed the high possibility of $69.5 \%$ to detect at least one thrombophilic genotype, including factor $V$ Leiden, 20210A prothrombin gene mutation, and methylene tetrahydrofolate reductase (MTHFR) gene mutation associated with high plasma homocysteine, in cirrhotic patients with PVT. ${ }^{45}$ This homeostatic profile was not consistent with a later study demonstrating that thrombophilic mutation was present in only $12 \%$ of cirrhotic patients with PVT. ${ }^{46}$ Among various inherited thrombophilic disorders, the G20210A prothrombin gene variant is the most common underlying hypercoagulable disorder in cirrhotic patients and carrying an odds ratio (OR) of 5.94 for the development of PVT. ${ }^{17}$ Myeloproliferative disorder secondary to the JAK2 V617F mutation was found in a significant proportion of cirrhotic patients with PVT. ${ }^{47}$ Other thrombophilic conditions, such as low level of ADAMTS13 (known as von Willebrand factor-cleaving protease) and resistance to the anticoagulant action of thrombomodulin, were observed in cirrhotic patients with PVT. ${ }^{48,49}$ The results of studies investigating the role of inherited thrombophilic disorder were summarized in Supplementary Table 2. ${ }^{17,45-49}$

The unstable coagulation balance can be tilted toward bleeding or thrombosis if any acute insult ensues. "Lowgrade" endotoxemia may play a pivotal role in activating the clotting system in the portal and systemic circulation and could represent an underlying mechanism for PVT in advanced liver disease. Lipopolysaccharide derived from gut microbiota has been shown to increase the systemic levels of factor VIII via stimulating its release by endothelial cells. ${ }^{50}$ Endotoxemia may be a determinant for splanchnic vasodilatation, which is a key factor for portal venous stasis. ${ }^{51}$ Together these findings indicate that endotoxemia is a plausible mechanism accounting for the increased risk of thrombosis in the portal circulation of cirrhotic patients.

\section{Risk factors of PVT other than thrombophilia}

The unbalanced hemostasis and alteration in splanchnic hemodynamic are more apparent in patients with advanced liver disease. An experimental study showed that factor II, antithrombin, and protein $C$ decreased progressively from Child-Turcotte-Pugh (CTP) class A to C. ${ }^{38}$ Furthermore, the decreasing plasma level of protein $C$ and antithrombin was well correlated with an increase in the model for end-stage liver disease (MELD) score. ${ }^{18}$ Additionally, cirrhotic patients with higher CTP scores are possibly more likely to have reduced portal vein flow associated with steal syndrome. ${ }^{20}$ Data from a recent large prospective study showed that the severity of liver disease at baseline was a significant predisposing factor associated with the development of PVT. ${ }^{23}$ Moreover, CTP class C was a significant predictor of mortality (hazard ratio [HR] 11.5, 95\% confidence interval [CI]: 6.9518.9). ${ }^{32}$

The etiology of liver disease also influences the occurrence of PVT. According to a study of 885 cirrhotic patients who underwent liver transplantation, PVT was found in $3.6 \%$ of patients with primary sclerosing cholangitis, $8 \%$ with primary biliary cholangitis, $16 \%$ with alcoholic and hepatitis B virusrelated cirrhosis, and mounting to $35 \%$ in patients with hepatocellular carcinoma (HCC). ${ }^{5}$ Emerging information from large transplant registries suggests that nonalcoholic steatohepatitis may be an independent risk factor for the development of nontumoral PVT in patients with decompensated cirrhosis. ${ }^{29,30}$ A recent cohort in the United States also showed that nonalcoholic steatohepatitis-related liver cirrhosis was significantly associated with the development of PVT (HR of 5.34, 95\% CI: 1.53-18.7). ${ }^{36}$

Intraabdominal surgery (hepatectomy, shunt surgery) and local regional therapy for HCC have been reported as determinants of PVT, due to venous injury and disturbance of blood flow after intervention. ${ }^{33}$

\section{Clinical manifestations of PVT in patients with cirrhosis}

The clinical presentation of PVT is variable. PVT in patients with cirrhosis is frequently asymptomatic due to splanchnic decompression through an existing spontaneous portosystemic shunt. In the completely acute occlusion of the portal vein, PVT may develop acute abdominal pain, which raises a concern of the extension to the SMV and mesenteric arches, causing intestinal ischemia and, ultimately, bowel infarction. In a previously stable cirrhotic patient, new onset of symptoms related to worsening portal hypertension, such as the development of variceal bleeding and refractory ascites, may suggest the development of PVT and should be thoroughly evaluated.

After a few weeks, the obstructed part of the portal vein is bypassed through the formation of venous collaterals that bring blood - in a hepatopetal manner - around the area of obstruction, known as portal cavernoma. The network of collateral portal veins characterizes chronic PVT. In most cirrhotic patients, chronic PVT is asymptomatic and discovered incidentally during abdominal imaging for HCC surveillance. Patients with chronic PVT frequently have esophageal or gastric varices, and the most common clinical presentation is gastrointestinal bleeding. ${ }^{17}$ Patients may have symptoms related to cirrhosis or other conditions, such as HCC, that predispose the development of PVT. Portal cholangiopathy, which compresses the large bile ducts by the paracholedochal collaterals, is also common in cirrhotic patients with longstanding chronic PVT. ${ }^{52}$ Some patients with portal cholangiopathy develop biliary complications, including pruritus, obstructive jaundice, and cholangitis. ${ }^{53,54}$

\section{Natural history of PVT in cirrhosis}

Spontaneous resolution of PVT has been described from $45 \%$ to $70 \%$ of cases in different cohorts. ${ }^{29,55,56}$ The spontaneous recanalization was reported to occur after a median follow-up of 5 months. ${ }^{1}$ To date, data regarding predictors of spontaneous recanalization is limited. In cohort studies evaluating the natural course of PVT, spontaneous recanalization was not associated with thrombus age, degree of PVT, location of thrombosis, and portal cavernoma. ${ }^{55,57}$ Only a cohort study by Maruyama et al. ${ }^{20}$ demonstrated that the diameter and flow volume in the largest collateral vessel at diagnosis of PVT was inversely associated with spontaneous improvement of PVT; however, the data require confirmation.

Recurrence of PVT after spontaneous recanalization has been reported in some cohorts, ranging from $21.3 \%$ during the mean follow-up of 47 months in the prospective cohort ${ }^{23}$ to $45 \%$ over an average follow-up of 63.3 months in the retrospective study. ${ }^{20}$ Hence, continuous monitoring of portal vein patency after spontaneous recanalization should be maintained at regular intervals. 


\section{Clinical impact of PVT in cirrhosis}

The impact of PVT on the natural course of cirrhosis is still debatable. PVT is generally thought to have a negative effect on prognosis because of a further increase in portal hypertension and worsening liver function caused by decreased liver perfusion and parenchymal atrophy. In particular, intrahepatic microvascular thrombosis secondary to liver necroinflammation may lead to liver ischemia, cell death, loss of functioning hepatic mass, and enhanced fibrogenesis through a process termed as "parenchymal extinction". ${ }^{58}$ This hypothesis has been supported by evidence that has indicated that primary prophylaxis of PVT with low dose low molecular weight heparin (LMWH) was effective in reducing mortality and risk of hepatic decompensation in patients with advanced cirrhosis. ${ }^{59}$ A recent meta-analysis involving 2436 cirrhotic patients demonstrated a significant association of PVT with both mortality and ascitic decompensation; it did not, however, evaluate the pooled effect of PVT on other features of hepatic decompensation, such as variceal bleeding. ${ }^{14} \mathrm{~A}$ prospective study by D'Amico et al. ${ }^{60}$ showed a more than 3 -fold higher risk of failure to control active variceal bleeding in cirrhotic patients with PVT, irrespective of treatment modality. Subsequently, a retrospective analysis by Dell'Era et al. ${ }^{61}$ highlighted that PVT was associated with a longer time to eradicate esophageal varies. Contrarily, a large prospective multicenter study following the incidence of PVT in cirrhosis overtime did not find a prognostic role of PVT, but mainly partial PVT on mortality and hepatic decompensation. ${ }^{23}$ Furthermore, Luca et al. ${ }^{55}$ found that spontaneous improvement of PVT did not provide any benefit in terms of the development of cirrhotic complications and survival. Based on these findings, it has been speculated that the progression or regression of partial PVT has no impact on the natural history of cirrhotic patients. However, evidence from a systematic review of the literature concluded that the presence of PVT might be associated with the long-term mortality in nontransplant patients with liver cirrhosis but not with the short-term mortality. ${ }^{62}$ Considering heterogeneity in data reporting and lengths of follow-up among studies, the reproducibility of these findings remains to be confirmed.

Historically, PVT poses relevant challenges during liver transplantation due to an increase in operative technical complexity, transfusion requirements and re-interventions, and lowers it the survival rate. ${ }^{63}$ According to the results of many transplant centers, the survival rates in the transplant setting mainly depend on PVT type and surgical technique. ${ }^{64,65}$ In particular, the presence of PVT, especially complete occlusion, negatively affected the 1 -year survival of liver transplant recipients with no impact on 5 -year survival. ${ }^{64}$ Furthermore, several alternative surgical techniques, other than conventional portal vein end-to-end anastomosis, were found to be associated with low survival rates. ${ }^{65,66}$ In an analysis of the registry of transplant recipients in the USA during 20012007, PVT was found to be associated with significantly higher posttransplant mortality but to not affect waiting list mortality. ${ }^{24,28,67}$ This finding was further extended by a recent analysis of the USA's transplant registry, which demonstrated that preexisting PVT significantly increased liver allograft failure and risk of death after liver transplant at 90 days, 1 year, 3 years, and 5 years. ${ }^{27}$

\section{Diagnosis}

The diagnosis of PVT includes abdominal imaging to demonstrate portal vein occlusion. As such, patients should undergo an evaluation to identify conditions that may predispose to PVT formation. In acute PVT, there will be evidence of portal vein occlusion without radiographic signs suggestive of chronic PVT, such as cavernous portal transformation. A Doppler ultrasound is a reasonable initial approach. The characteristic ultrasound findings are the presence of solid echo within the portal vein or branches combined with the absence of portal flow (Fig. 2A-B). The ultrasound has a reported overall sensitivity of $89-93 \%$ and specificity of $92-99 \%$ for the detection of PVT. ${ }^{68,69}$ However, it is not sensitive for determining the extent of thrombus, especially in the SMV. ${ }^{70}$

If the ultrasound suggests PVT, an abdominal computed tomography (CT) scan can then be obtained. The classic feature of acute PVT is the presence of hyperattenuating material in the portal vein in a CT scan without contrast. Imaging after intravenous contrast injection may reveal a lack of luminal enhancement, increased hepatic enhancement in the arterial phase, and decreased hepatic enhancement in the portal phase. ${ }^{71}$ However, it is observed when the imaging study is done within 30 days after the onset of symptoms. ${ }^{72}$ Chronic thrombosis is characterized by the presence of portal cavernoma, reportedly seen as soon as 6 days after portal vein occlusion (Fig. 2C-D). ${ }^{70}$ However, chronic PVT may be difficult to define accurately because enlarged collateral vessels may preexist as a consequence of cirrhosis. ${ }^{73}$

Contrast-enhanced $\mathrm{CT}$ and magnetic resonance imaging (MRI) are excellent modalities to evaluate the extension of thrombus and may detect predisposing conditions or intestinal ischemia. CT angiography has a reported $90 \%$ sensitivity and $99 \%$ specificity for the diagnosis of PVT, according to operative findings being used as a reference. ${ }^{69}$ MRI has $100 \%$ sensitivity and $98 \%$ specificity for detecting PVT. ${ }^{74,75}$ Overall, various imaging modalities have higher sensitivity in detecting complete PVT when compared to partial PVT $(65 \%$ and $39 \%$, respectively) with comparable specificity ( $99 \%$ and $97 \%$, respectively). ${ }^{76}$

A new probability assessment tool for the development or presence of PVT in patients with cirrhosis was recently proposed. ${ }^{12}$ Three major criteria include CTP class B or C cirrhosis, prior history of resolved PVT, and presence of thrombophilic disorder. In contrast, seven minor criteria are the evidence of portosystemic shunt, active hepatocellular malignancy, history of systemic venous thrombosis or abortion, recent abdominal intervention, reduced portal flow velocity $<15 \mathrm{~cm} / \mathrm{s}$, and clinical presentation with acute abdomen or worsening of portal hypertension in cirrhotic patients. The presence of two major, or one major and two minor or four minor criteria indicates a high probability. However, further validation from a prospective study is needed.

Accurate differentiation between nontumoral and malignant PVT in cirrhotic patients is of paramount importance. Visualized thrombus in the portal vein is considered nontumoral PVT when all of the following characteristics are present: lack of enhancement of endoluminal material during the arterial phase of contrast administration, absence of mass forming features, and absence of wall disruption of portal vein or tumor encroaching on the portal vein. ${ }^{77}$ The presence of neovascularization or main portal vein diameter $>23 \mathrm{~mm}$ showed a sensitivity of $86 \%$ and specificity of $100 \%$ 

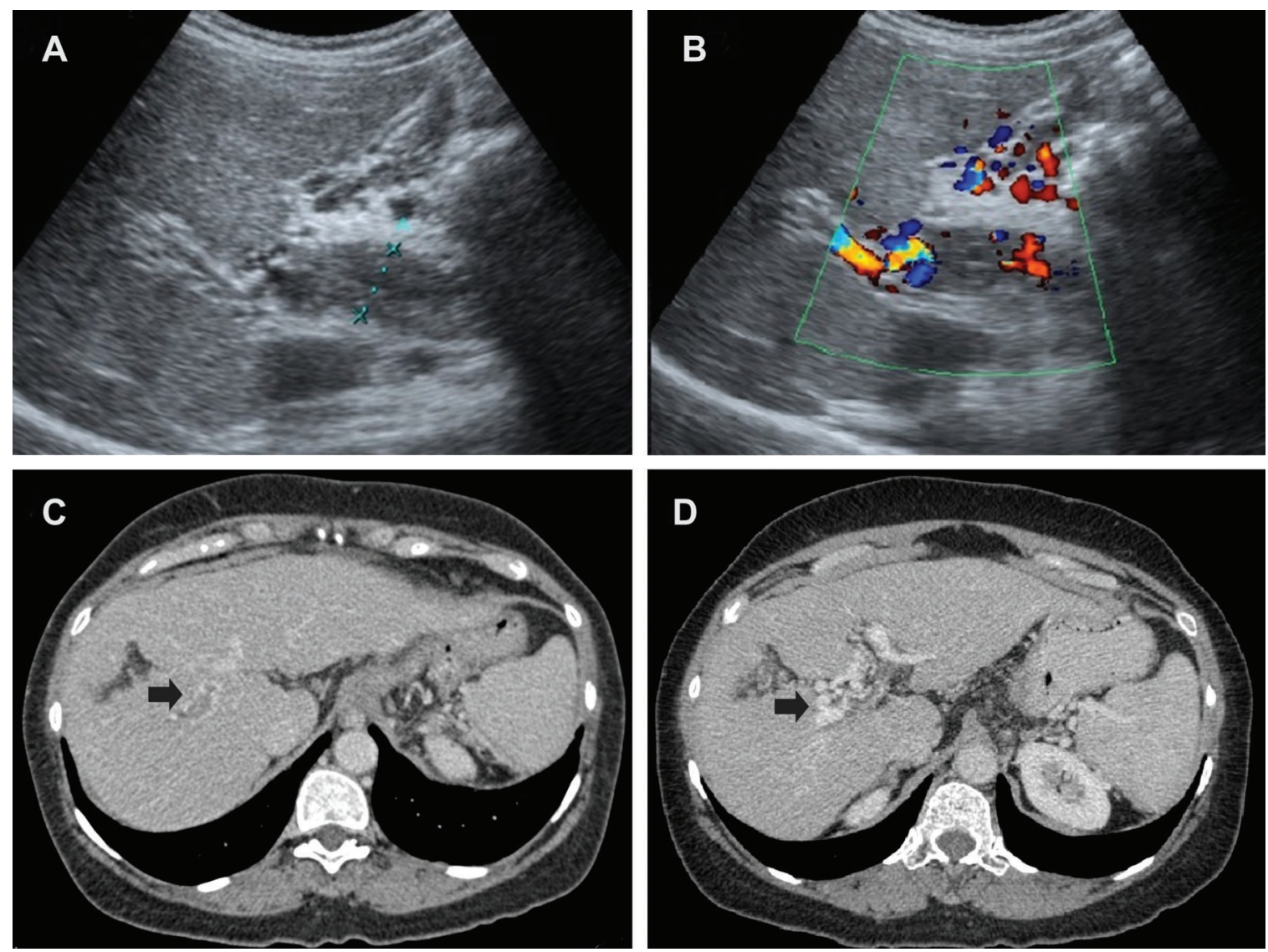

Fig. 2. Imaging findings of nontumoral portal vein thrombosis (PVT) in liver cirrhosis. (A) Ultrasound of the abdomen shows an echogenic material within the dilated portal vein, indicating PVT. (B) Doppler ultrasound of the abdomen shows decreased color flow within the main portal vein and demonstrates color-filled dilated collateral vessels around the porta hepatis consistent with cavernous transformation. (C) Computed tomography of the abdomen on portal venous phase shows a filling defect in the right branch of the portal vein (arrow), indicating thrombus. (D) Contrast-enhanced computed tomography depicts cavernous transformation (arrow) following portal venous thrombosis.

for the diagnosis of malignant PVT. ${ }^{78}$ If uncertainty persists, a CT-guided biopsy for histological examination may be required.

\section{Management}

The optimal management of PVT in the setting of liver cirrhosis regarding the appropriate strategies, the magnitude of PVT (occlusive versus nonocclusive, acute versus chronic), type and timing of anticoagulation, and the role of a transjugular intrahepatic portal shunt (TIPS) are lacking. In 2009, the American Association for the Study of Liver Diseases (AASLD) published guidelines for the management of PVT in cirrhosis. They did not provide specific anticoagulation guidance for PVT but recommended clinical decisions be made on a case-by-case basis depending on the presence of thrombophilic conditions, symptoms, or extension to the SMV. ${ }^{2}$ The European Association for the Study of the Liver (EASL) published guidelines on vascular disorders of the liver in 2016 and recommended evaluating for the presence of at-risk varices and initiating therapy with band ligation or nonselective $\beta$ blocker before initiation of anticoagulation treatment for PVT in cirrhosis. ${ }^{3}$ According to the EASL guideline, anticoagulation treatment is advised for at least 6 months in cirrhotic patients with PVT and should be continued for some months after portal vein repermeation or until transplant in candidates for liver transplantation. ${ }^{3}$ Like AASLD and
EASL guidelines, the Baveno VI consensus statement does not make recommendations on the choice of anticoagulation therapy for PVT due to limited data. ${ }^{11}$ The indication, contraindication, and currently available therapeutic agents are summarized in Supplementary Table 3. ${ }^{1-3,11,25,46,79-93}$

\section{Anticoagulation}

Anticoagulation is the primary management of acute PVT, with supporting evidence of high efficacy and a favorable safety profile (Table 1 ). The objective is to achieve recanalization of the portal vein and prevent the extension of the thrombus to decrease the notorious consequences of portal hypertension and mesenteric ischemia and allow conventional end-to-end portal vein anastomosis to be technically possible in transplant candidates. ${ }^{35}$ Currently, available guidelines recommend that anticoagulation should be considered in liver transplantation candidates with thrombosis of the main portal vein trunk or progressive PVT. ${ }^{2,3,11}$ For noncandidates to liver transplantation, no recommendation regarding anticoagulation treatment has been made. However, anticoagulation could be considered in selected cases with symptomatic acute occlusive PVT, the extension to the SMV, or known strong prothrombophilic conditions. ${ }^{11}$ 
Clinical data suggest that anticoagulation and recanalization of the portal vein are associated with reduced portal hypertension-related events and improved survival. ${ }^{80}$ Anticoagulation therapy in cirrhotic patients with PVT has shown the variability in the resolution of thrombosis. The degree of PVT at diagnosis does not predict the likelihood of response to anticoagulation, ${ }^{81,94}$ but extensive PVT before treatment decreases the likelihood of recanalization. ${ }^{46,57}$ The successful management of PVT in cirrhosis is strongly associated with early diagnosis and initiation of anticoagulation within the first 6 months. ${ }^{46}$ The presence of portal cavernoma indicates a long-standing PVT that is unlikely to recanalize completely with anticoagulation. A relatively low recanalization rate of complete PVT after anticoagulation therapy suggests its limited usefulness in cirrhotic patients with complete PVT. Anticoagulants evaluated in these studies included vitamin $\mathrm{K}$ antagonist (VKA), LMWH, and direct oral anticoagulant (DOAC). ${ }^{1,25,46,57,79-86,94-97}$

In the acute setting of PVT, LMWH is the preferred agent, typically followed by VKA. LMWH has the advantage of a fixeddose regimen without laboratory monitoring; however, daily subcutaneous administration may reduce compliance and require dose adjustment according to renal function that is relatively fragile in patients with advanced liver cirrhosis. VKA is generally considered for long-term anticoagulation therapy, but maintaining the international normalized ratio in the therapeutic range throughout treatment and interference with the MELD score makes its use challenging. The risk and benefits of treatment with anticoagulants for PVT in cirrhosis have been debated. Compelling evidence from two meta-analyses showed that traditional anticoagulants significantly increased the rate of PVT recanalization ( $71 \%$ vs. $42 \%$ ) with the OR of 4.16 ( $95 \% \mathrm{CI}$ : $1.88-9.20$ ) and lower the rate of PVT progression ( $9 \%$ vs. $33 \%$ ) compared with no anticoagulation therapy. ${ }^{98,99}$ Both LMWH and warfarin were effective in preventing the progression of thrombosis. However, LMWH, not warfarin, was significantly associated with complete PVT resolution. ${ }^{98}$ Recurrence after discontinuation of anticoagulation therapy following clot resolution was found to be up to $38 \% .{ }^{79}$ The most feared consequence of anticoagulation is bleeding. However, major and minor bleeding risk related to anticoagulation therapy for PVT in cirrhosis ranges from $3.3 \%$ to $11 \%$, which is not different from that of no treatment. ${ }^{98,99}$

DOACs are more widely used in clinical practice for treatment and prevention of venous thromboembolic events due to an acceptable safety profile and availability of antidotes without the need for drug monitoring. Studies examining the pharmacodynamics of DOAC in patients with cirrhosis showed that the anticoagulant effect might be altered in advanced cirrhosis. ${ }^{100,101}$ Data regarding the efficacy and safety of DOACs for treatment of PVT in cirrhosis are emerging but remain limited, as shown in Table $1 .^{85,86,96,97}$ Nagaoki et al. ${ }^{86}$ randomized 50 cirrhotic patients with variable CTP scores and PVT to receive either warfarin or edoxaban for 6 months after 2 weeks of daparinoid sodium therapy. They reported a significantly higher rate of complete resolution of PVT with the slower progression of PVT in patients receiving edoxaban and no difference in adverse effects among both treatment groups.

Furthermore, Hanafy et al. ${ }^{85}$ reported a randomized controlled trial of rivaroxaban versus warfarin for the management of acute PVT in 80 patients with hepatitis C cirrhosis who had undergone splenectomy due to symptomatic hypersplenism. Patients receiving rivaroxaban achieved a higher frequency of recanalization of the portal vein with better short-term survival rates than patients receiving warfarin.
Complications such as major bleeding, abnormal liver functions, or death did not occur in the rivaroxaban group, while the warfarin group experienced ascites, gastrointestinal bleeding, encephalopathy, and death. Although the results are promising, rivaroxaban is not the ideal DOAC for patients with cirrhosis due to higher reported rates of hepatotoxicity with rivaroxaban than other DOACs. ${ }^{102}$ Given the small sample size and heterogeneous population of each study, the safety and efficacy of DOACs for PVT in patients with cirrhosis need to be further ascertained.

\section{Transjugular portosystemic shunt}

The advantages of TIPS for the treatment of PVT in patients with cirrhosis are to recanalize the thrombosed portal vein using endovascular techniques effectively and simultaneously resolve symptomatic portal hypertension and prevent thrombus recurrence or extension by the creation of a portosystemic shunt. ${ }^{103}$ Nowadays, TIPS represents an effective adjunctive therapy for PVT if anticoagulation is ineffective or inappropriate. Transplenic TIPS placement is feasible in patients with complete obliterative PVT to recanalize the portal vein in anticipation of transplantation. ${ }^{90,93}$ The technical success rate for TIPS is relatively high in experienced centers. ${ }^{9,90-93}$ In a recent meta-analysis of 13 studies including 399 patients ( $92 \%$ cirrhosis; PVT: complete $46 \%$, chronic $87 \%$, portal cavernoma $15 \%$ ), TIPS was technically feasible in $95 \%$ of cases, carried a moderate risk of significant complication (10\%), and was highly effective in achieving sustained recanalization of PVT (79\%), even in cases with the cavernous transformation. ${ }^{89}$ This result means that TIPS can be effective in maintaining long-term portal vein patency, allowing avoidance of anticoagulation therapy. Regarding the clinical outcome of this procedure in the management of PVT, the pooled 12month survival rate was $89 \%$. This finding supports previous reports suggesting that TIPS likely confers survival benefit in patients with advanced liver cirrhosis. ${ }^{104-106}$ A retrospective analysis of 57 cirrhotic patients with nontumoral PVT undergoing TIPS and subsequent systemic anticoagulation showed that the independent factors associated with technical success were SMV involvement (OR: 42.8; 95\% CI: 1.43-1282) and presence of portal cavernoma (OR: 37.5 ; 95\% CI: $1.96-$ $720) .{ }^{92}$ Therefore, careful consideration is needed, especially in patients with these negative predictive factors. Given the heterogeneity of published data, adequately powered clinical trials comparing TIPS to anticoagulation are required to guide clinical decision-making in this field.

\section{Challenges of liver transplantation in cirrhotic patients} with nontumoral PVT

Currently, the presence of PVT is no longer an absolute contraindication for liver transplantation. The first successful liver transplantation in a patient with PVT was reported in $1985 .^{107}$ Since then, the advancement of surgical techniques has allowed end-to-end anastomosis to be performed in the majority of cases. ${ }^{26}$ Physiological portal inflow is defined when splanchnic venous blood from splanchnic vessels or large portosystemic shunt can be redirected to the liver graft. ${ }^{108}$ Previous studies showed no significant differences in survival between patients with complete and partial PVT, given that physiological portal flow was established. ${ }^{65}$ However, liver transplantation in patients with extensive thrombosis remains technically challenging. ${ }^{31} \mathrm{~A}$ recent 
Rugivarodom M. et al: Portal vein thrombosis in cirrhosis

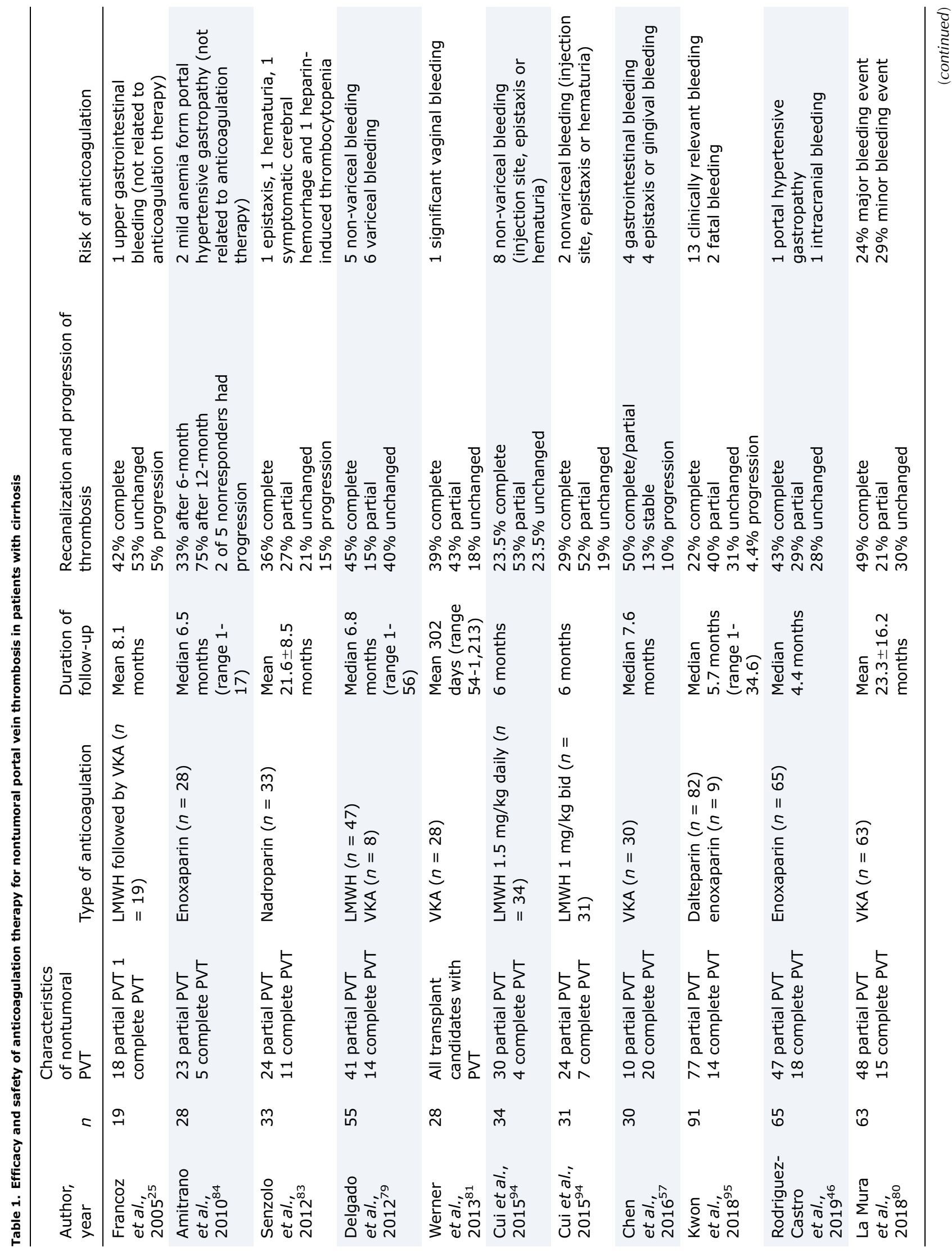




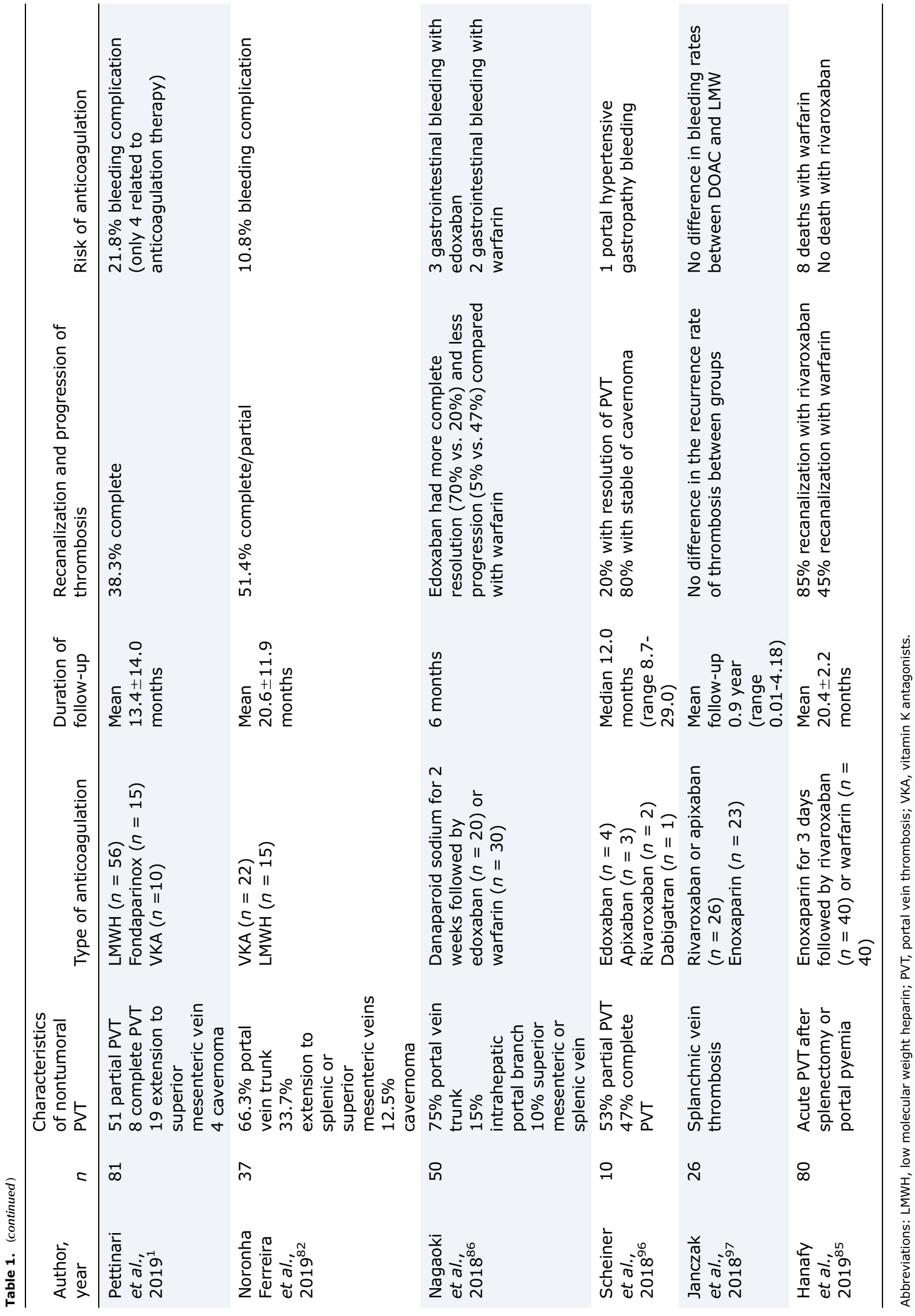


meta-analysis showed that 30-day mortality was higher in recipients with complete PVT than in those with partial thrombosis. ${ }^{109}$ Of note, the survival rate is decreased in those with nonphysiologic portal anastomosis. ${ }^{35,65}$ In patients with grade I-III PVT, according to Yerdel classification, ${ }^{6}$ the thrombus was removed by eversion thrombectomy or thromboendovenectomy (removal of clot and attached intimal layer). If the portal flow is insufficient, various surgical options can be considered to increase the inflow, including ligation of the portosystemic collaterals, portal vein arterialization, interposition graft between patent splanchnic vessels, and portal vein or a jump graft from SMV to donor portal vein. ${ }^{31}$ In grade IV PVT with the presence of portosystemic shunt, using systemic veins as the inflow vessels including renoportal anastomosis, left gastric vein to portal vein anastomosis and pericholedochal varix to portal vein anastomosis allows restoration of physiologic portal hemodynamic. ${ }^{108}$ In the absence of portosystemic collaterals, surgical alternatives are reno-portal anastomosis, cavoportal hemitransposition, and multivisceral transplantation. ${ }^{108}$ Cautiously, these nonphysiologic anastomoses, except reno-portal anastomosis in patients with patent surgical splenorenal shunt, do not reverse portal hypertension. ${ }^{35}$ Multivisceral transplantation, including liver and small bowel, was theoretically the best option to restore physiologic portal flow and reverse portal hypertension in a patient with extensive PVT. However, the experience is very limited. The initial report of 25 patients with grade IV PVT who underwent multivisceral transplantation showed the relatively favorable 1-, 3- and 5-survival rates of $80 \%, 72 \%$, and $72 \%$, respectively. ${ }^{110}$

PVT is not considered a MELD exception; therefore, patients with PVT do not receive additional points for organ allocation. ${ }^{35}$
However, cirrhotic patients with PVT should be transplanted before reaching a MELD score of $30 .{ }^{111}$ The living donor liver transplantation in patients with PVT poses characteristic obstacles. The restricted availability of a vein graft is the main technical challenge. In addition, the safety of the donor is of paramount importance. Contrarily, considering living donor liver transplantation in patients with grade I-III PVT may be reasonable in highly experienced centers. ${ }^{112,113}$

After liver transplantation, the hemodynamic alteration of splanchnic circulation was restored, resulting in a low rate of rethrombosis (less than 5\%); therefore, long term anticoagulation is not justified. ${ }^{35,112}$ However, the consideration of systemic anticoagulation therapy patients with extensive thrombosis and nonphysiologic reconstruction who carry a high risk of rethrombosis needs to be done on a case-by-case basis.

\section{Potential algorithm for the management of PVT in cirrhosis}

Based on existing data and international society recommendations, we propose a potential algorithm for the management of PVT in liver cirrhosis (Fig. 3). First, patients with cirrhosis awaiting liver transplantation should be screened for PVT at least every 6 months with Doppler ultrasound. Detection of PVT before transplantation would help in surgical planning and allow potential preoperative therapy to recanalize the portal vein. It seems logical that cirrhotic patients with risk factors for PVT (especially those with portal flow velocity $<15 \mathrm{~cm} / \mathrm{s}$ or decompensated cirrhosis) should be screened for the development of PVT every 6 months. Second, patients with cirrhosis diagnosed with PVT by Doppler ultrasound should be assessed with contrast-enhanced imaging to confirm and stage

\section{PVT in cirrhosis}

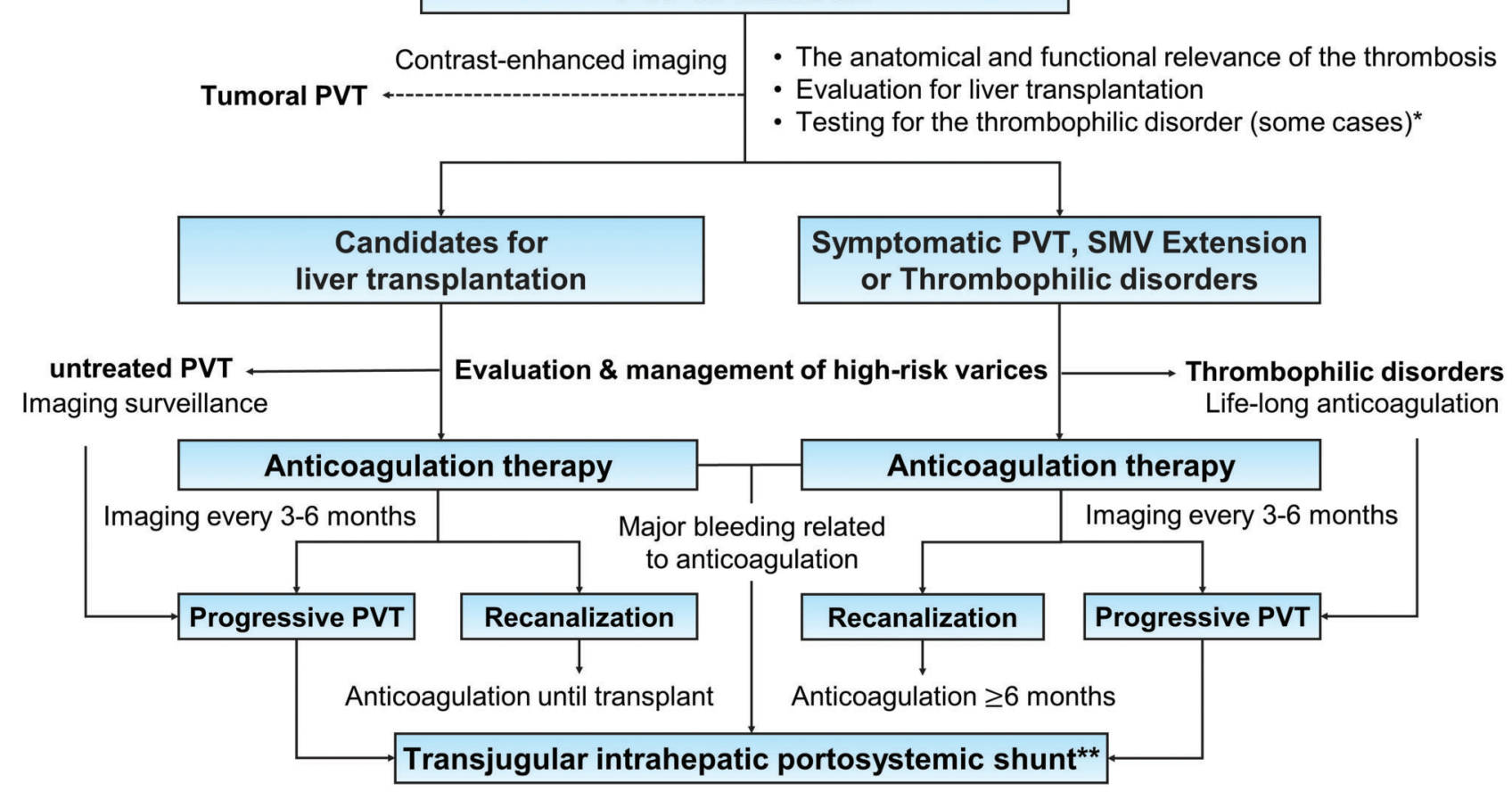

Fig. 3. Potential algorithm for the management of nontumoral portal vein thrombosis (PVT) in liver cirrhosis. *Lupus anticoagulant, anticardiolipin, anti- $\beta 2-$ glycoprotein 1 antibody, factor $\mathrm{V}$ Leiden, 20210A prothrombin gene mutation, methylene tetrahydrofolate reductase gene mutation, JAK2 V617F mutation and work-up for paroxysmal nocturnal hemoglobinuria. ${ }^{*}$ Limited technical feasibility in low-volume center, superior mesenteric vein (SMV) thrombosis and portal cavernoma. 
the extent of nontumoral thrombosis. Third, evaluation for liver transplantation should be considered once cirrhotic patients have experienced an index complication, such as ascites, hepatic encephalopathy, or variceal hemorrhage or hepatocellular dysfunction resulting in a MELD score $\geq 15$. Fourth, testing for acquired and inherited thrombophilic disorders can be considered in cirrhotic patients with PVT on an individual basis, but universal screening is not currently recommended. Fifth, the assessment of bleeding risk and the benefit of anticoagulation therapy is crucial. Patients should undergo an upper endoscopy to assess for portal hypertension or other mucosal lesions. Subsequent prophylaxis with endoscopic band ligation or pharmacotherapy with nonselective $\beta$ blockers should be utilized for highrisk varices. Sixth, anticoagulation therapy should be considered for liver transplantation candidates, patients with symptomatic acute PVT, or progression of PVT or extension into the SMV. In cirrhotic patients with nonocclusive thrombosis of the trunk or a single branch of portal vein left untreated, imaging surveillance should be carried out every 3-6 months to evaluate for thrombosis progression. Seventh, the selection of the type of anticoagulation should be individualized. The limitation and benefits of each medication (LMWH, VKA, or DOACs) should be reviewed with the patients. Eighth, the optimal duration of anticoagulation may be at least 6 months to achieve the successful recanalization of the portal vein. In cases of underlying hypercoagulability or liver transplantation candidates, indefinite anticoagulation or treatment until liver transplantation may be considered. If anticoagulation treatment is stopped, close follow-up with abdominal imaging every 3-6 months is advised to evaluate for PVT recurrence. Lastly, TIPS should be considered for the treatment of PVT in patients with cirrhosis requiring treatment for clinically significant portal hypertension, patients with symptomatic and complete occlusion of the main portal vein, or those with progressive PVT despite adequate anticoagulation.

\section{Conclusions}

Nontumoral PVT is a challenging consequence of cirrhosis. Existing data have greatly expanded our knowledge of pathophysiology, natural history, and treatment of PVT in cirrhosis. Several case series have shown the efficacy and safety of the anticoagulation treatment and TIPS for the management of PVT in cirrhosis. However, research remains limited to mainly retrospective cohort studies so that any firm conclusions for clinical practice cannot be achieved. The potential risk and benefit of various treatment modalities should be evaluated in prospective and randomized trials. Treatment for nontumoral PVT in liver cirrhosis must be decided on a case-by-case basis.

\section{Funding}

None to declare.

\section{Conflict of interest}

The authors have no conflict of interests related to this publication.

\section{Author contributions}

Drafted the first version of the manuscript (MR), edited and revised the manuscript, and contributed to conceptual development of the study (PC).

\section{References}

[1] Pettinari I, Vukotic R, Stefanescu H, Pecorelli A, Morelli M, Grigoras C, et al. Clinical impact and safety of anticoagulants for portal vein thrombosis in cirrhosis. Am J Gastroenterol 2019;114:258-266. doi: 10.1038/s41395018-0421-0.

[2] DeLeve LD, Valla DC, Garcia-Tsao G. Vascular disorders of the liver. Hepatology 2009;49:1729-1764. doi: 10.1002/hep.22772.

[3] EASL Clinical Practice Guidelines: Vascular diseases of the liver. J Hepatol 2016;64:179-202. doi: 10.1016/j.jhep.2015.07.040.

[4] Stieber AC, Zetti G, Todo S, Tzakis AG, Fung J], Marino I, et al. The spectrum of portal vein thrombosis in liver transplantation. Ann Surg 1991;213:199206. doi: 10.1097/00000658-199103000-00003.

[5] Nonami T, Yokoyama I, Iwatsuki S, Starzl TE. The incidence of portal vein thrombosis at liver transplantation. Hepatology 1992;16:1195-1198.

[6] Yerdel MA, Gunson B, Mirza D, Karayalçin K, Olliff S, Buckels J, et al. Portal vein thrombosis in adults undergoing liver transplantation: risk factors, screening, management, and outcome. Transplantation 2000;69:18731881. doi: 10.1097/00007890-200005150-00023.

[7] Jamieson NV. Changing perspectives in portal vein thrombosis and liver transplantation. Transplantation 2000;69:1772-1774. doi: 10 . 1097/00007890-200005150-00006.

[8] Charco R, Fuster J, Fondevila C, Ferrer J, Mans E, García-Valdecasas JC. Portal vein thrombosis in liver transplantation. Transplant Proc 2005;37: 3904-3905. doi: 10.1016/j.transproceed.2005.09.120.

[9] Bauer J, Johnson S, Durham J, Ludkowski M, Trotter J, Bak T, et al. The role of TIPS for portal vein patency in liver transplant patients with portal vein thrombosis. Liver Transpl 2006;12:1544-1551. doi: 10.1002/It.20869.

[10] Ma J, Yan Z, Luo J, Liu Q, Wang J, Qiu S. Rational classification of portal vein thrombosis and its clinical significance. PLoS One 2014;9:e112501. doi: 10. 1371/journal.pone.0112501.

[11] de Franchis R. Expanding consensus in portal hypertension: Report of the Baveno VI Consensus Workshop: Stratifying risk and individualizing care for portal hypertension. J Hepatol 2015;63:743-752. doi: 10.1016/j.jhep. 2015.05.022.

[12] Sarin SK, Philips CA, Kamath PS, Choudhury A, Maruyama H, Nery FG, et al. Toward a comprehensive new classification of portal vein thrombosis in patients with cirrhosis. Gastroenterology 2016;151:574-577.e3. doi: 10. 1053/j.gastro.2016.08.033.

[13] Tripodi A, Mannucci PM. The coagulopathy of chronic liver disease. N Engl J Med 2011;365:147-156. doi: 10.1056/NEJMra1011170.

[14] Stine JG, Shah PM, Cornella SL, Rudnick SR, Ghabril MS, Stukenborg GJ, et al. Portal vein thrombosis, mortality and hepatic decompensation in patients with cirrhosis: A meta-analysis. World J Hepatol 2015;7:27742780. doi: 10.4254/wjh.v7.i27.2774.

[15] Intagliata NM, Argo CK, Stine JG, Lisman T, Caldwell SH, Violi F. Concepts and controversies in haemostasis and thrombosis associated with liver disease: Proceedings of the 7th International Coagulation in Liver Disease Conference. Thromb Haemost 2018;118:1491-1506. doi: 10.1055/s0038-1666861.

[16] Okuda K, Ohnishi K, Kimura K, Matsutani S, Sumida M, Goto N, et al. Incidence of portal vein thrombosis in liver cirrhosis. An angiographic study in 708 patients. Gastroenterology 1985;89:279-286. doi: 10.1016/00165085(85)90327-0.

[17] Amitrano L, Guardascione MA, Brancaccio V, Margaglione M, Manguso F, Iannaccone $L$, et al. Risk factors and clinical presentation of portal vein thrombosis in patients with liver cirrhosis. J Hepatol 2004;40:736-741. doi: 10.1016/j.jhep.2004.01.001.

[18] Zocco MA, Di Stasio E, De Cristofaro R, Novi M, Ainora ME, Ponziani F, et al. Thrombotic risk factors in patients with liver cirrhosis: correlation with MELD scoring system and portal vein thrombosis development. J Hepatol 2009;51:682-689. doi: 10.1016/j.jhep.2009.03.013.

[19] Tsochatzis EA, Senzolo M, Germani G, Gatt A, Burroughs AK. Systematic review: portal vein thrombosis in cirrhosis. Aliment Pharmacol Ther 2010; 31:366-374. doi: 10.1111/j.1365-2036.2009.04182.x.

[20] Maruyama H, Okugawa H, Takahashi M, Yokosuka O. De novo portal vein thrombosis in virus-related cirrhosis: predictive factors and long-term outcomes. Am J Gastroenterol 2013;108:568-574. doi: 10.1038/ajg.2012. 452.

[21] Violi F, Corazza GR, Caldwell SH, Perticone F, Gatta A, Angelico M, et al. Portal vein thrombosis relevance on liver cirrhosis: Italian Venous Thrombotic Events Registry. Intern Emerg Med 2016;11:1059-1066. doi: 10. 1007/s11739-016-1416-8.

[22] Violi F, Ferro D. Clotting activation and hyperfibrinolysis in cirrhosis: implication for bleeding and thrombosis. Semin Thromb Hemost 2013;39:426433. doi: $10.1055 / \mathrm{s}-0033-1334144$.

[23] Nery F, Chevret S, Condat B, de Raucourt E, Boudaoud L, Rautou PE, et al. Causes and consequences of portal vein thrombosis in 1,243 patients with 
cirrhosis: results of a longitudinal study. Hepatology 2015;61:660-667. doi: $10.1002 /$ hep. 27546

[24] Suarez Artacho G, Barrera Pulido L, Alamo Martinez JM, Serrano DiezCanedo J, Bernal Bellido C, Marín Gomez LM, et al. Outcomes of liver transplantation in candidates with portal vein thrombosis. Transplant Proc 2010; 42:3156-3158. doi: 10.1016/j.transproceed.2010.05.057.

[25] Francoz C, Belghiti J, Vilgrain V, Sommacale D, Paradis V, Condat B, et al. Splanchnic vein thrombosis in candidates for liver transplantation: usefulness of screening and anticoagulation. Gut 2005;54:691-697. doi: 10 . 1136/gut.2004.042796.

[26] Rodríguez-Castro KI, Porte RJ, Nadal E, Germani G, Burra P, Senzolo M. Management of nonneoplastic portal vein thrombosis in the setting of liver transplantation: a systematic review. Transplantation 2012;94: 1145-1153. doi: 10.1097/TP.0b013e31826e8e53.

[27] Ghabril M, Agarwal S, Lacerda M, Chalasani N, Kwo P, Tector AJ. Portal vein thrombosis is a risk factor for poor early outcomes after liver transplantation: Analysis of risk factors and outcomes for portal vein thrombosis in waitlisted patients. Transplantation 2016;100:126-133. doi: 10.1097/TP. 0000000000000785

[28] Englesbe MJ, Kubus J, Muhammad W, Sonnenday C], Welling T, Punch JD, et al. Portal vein thrombosis and survival in patients with cirrhosis. Liver Transpl 2010;16:83-90. doi: 10.1002/lt.21941.

[29] Stine JG, Shah NL, Argo CK, Pelletier SJ, Caldwell SH, Northup PG. Increased risk of portal vein thrombosis in patients with cirrhosis due to nonalcoholic steatohepatitis. Liver Transpl 2015;21:1016-1021. doi: 10. 1002/It.24134.

[30] Stine JG, Argo CK, Pelletier SJ, Maluf DG, Caldwell SH, Northup PG. Advanced non-alcoholic steatohepatitis cirrhosis: A high-risk population for pre-liver transplant portal vein thrombosis. World J Hepatol 2017;9: 139-146. doi: 10.4254/wjh.v9.i3.139.

[31] Chen H, Turon F, Hernández-Gea V, Fuster J, Garcia-Criado A, Barrufet M, et al. Nontumoral portal vein thrombosis in patients awaiting liver transplantation. Liver Transpl 2016;22:352-365. doi: 10.1002/lt.24387.

[32] Violi F, Corazza GR, Caldwell SH, Talerico G, Romiti GF, Napoleone L, et al. Incidence and recurrence of portal vein thrombosis in cirrhotic patients. Thromb Haemost 2019;119:496-499. doi: 10.1055/s-0038-1676981.

[33] Intagliata NM, Caldwell SH, Tripodi A. Diagnosis, development, and treatment of portal vein thrombosis in patients with and without cirrhosis. Gastroenterology 2019;156:1582-1599.e1. doi: 10.1053/j.gastro.2019.01. 265.

[34] Rajani R, Björnsson E, Bergquist A, Danielsson A, Gustavsson A, Grip O, et al. The epidemiology and clinical features of portal vein thrombosis: a multicentre study. Aliment Pharmacol Ther 2010;32:1154-1162. doi: 10. 1111/j.1365-2036.2010.04454.x

[35] Francoz C, Valla D, Durand F. Portal vein thrombosis, cirrhosis, and liver transplantation. J Hepatol 2012;57:203-212. doi: 10.1016/j.jhep.2011. 12.034.

[36] Stine JG, Wang J, Shah PM, Argo CK, Intagliata N, Uflacker A, et al. Decreased portal vein velocity is predictive of the development of portal vein thrombosis: A matched case-control study. Liver Int 2018;38:94101. doi: $10.1111 /$ liv. 13500 .

[37] Tripodi A, Primignani M, Lemma L, Chantarangkul V, Dell'Era A, Iannuzzi F, et al. Detection of the imbalance of procoagulant versus anticoagulant factors in cirrhosis by a simple laboratory method. Hepatology 2010;52: 249-255. doi: 10.1002/hep.23653.

[38] Tripodi A, Primignani M, Chantarangkul V, Dell'Era A, Clerici M, de Franchis $\mathrm{R}$, et al. An imbalance of pro- vs anti-coagulation factors in plasma from patients with cirrhosis. Gastroenterology 2009;137:2105-2111. doi: 10 . 1053/j.gastro.2009.08.045.

[39] O'Leary JG, Greenberg CS, Patton HM, Caldwell SH. AGA clinical practice update: Coagulation in cirrhosis. Gastroenterology 2019;157:34-43.e1. doi: $10.1053 /$ j.gastro.2019.03.070

[40] Kumar M, Ahmad J, Maiwall R, Choudhury A, Bajpai M, Mitra LG, et al. Thromboelastography-guided blood component use in patients with cirrhosis with nonvariceal bleeding: A randomized controlled trial. Hepatology 2020;71:235-246. doi: 10.1002/hep.30794.

[41] De Pietri L, Bianchini M, Montalti R, De Maria N, Di Maira T, Begliomini B, et al. Thrombelastography-guided blood product use before invasive procedures in cirrhosis with severe coagulopathy: A randomized, controlled trial. Hepatology 2016;63:566-573. doi: 10.1002/hep.28148.

[42] Kapoor S, Pal S, Sahni P, Chattopadhyay TK. Thromboelastographic evaluation of coagulation in patients with extrahepatic portal vein thrombosis and non-cirrhotic portal fibrosis: a pilot study. J Gastroenterol Hepatol 2009;24: 992-997. doi: 10.1111/j.1440-1746.2008.05761.x

[43] Wu L, Zhang G, Guo C. Thromboelastography detects possible coagulation disturbance in pediatric patients with portal cavernoma. Transfus Med Hemother 2020;47:135-143. doi: 10.1159/000501229.

[44] Huang $X$, Fan X, Zhang R, Jiang S, Yang K, Chen S. Systemic inflammation and portal vein thrombosis in cirrhotic patients with gastroesophageal varices. Eur J Gastroenterol Hepatol 2020;32:401-405. doi: 10. 1097/MEG.0000000000001526.

[45] Amitrano L, Brancaccio V, Guardascione MA, Margaglione M, Iannaccone L, $D^{\prime}$ Andrea $G$, et al. Inherited coagulation disorders in cirrhotic patients with portal vein thrombosis. Hepatology 2000;31:345-348. doi: 10.1002/hep. 510310213

[46] Rodriguez-Castro KI, Vitale A, Fadin M, Shalaby S, Zerbinati P, Sartori MT, et al. A prediction model for successful anticoagulation in cirrhotic porta vein thrombosis. Eur J Gastroenterol Hepatol 2019;31:34-42. doi: 10. 1097/MEG.0000000000001237.

[47] Saugel B, Lee M, Feichtinger S, Hapfelmeier A, Schmid RM, Siveke JT. Thrombophilic factor analysis in cirrhotic patients with portal vein thrombosis. J Thromb Thrombolysis 2015;40:54-60. doi: 10.1007/s11239-0141124-z.

[48] La Mura V, Tripodi A, Tosetti G, Cavallaro F, Chantarangkul V, Colombo M, et al. Resistance to thrombomodulin is associated with de novo portal vein thrombosis and low survival in patients with cirrhosis. Liver Int 2016;36: 1322-1330. doi: 10.1111/liv.13087.

[49] Lancellotti S, Basso M, Veca V, Sacco M, Riccardi L, Pompili M, et al. Presence of portal vein thrombosis in liver cirrhosis is strongly associated with low levels of ADAMTS-13: a pilot study. Intern Emerg Med 2016;11:959967. doi: 10.1007/s11739-016-1467-x.

[50] Carnevale R, Raparelli V, Nocella C, Bartimoccia S, Novo M, Severino A, et al. Gut-derived endotoxin stimulates factor VIII secretion from endothelial cells. Implications for hypercoagulability in cirrhosis. J Hepatol 2017;67: 950-956. doi: 10.1016/j.jhep.2017.07.002.

[51] Violi F, Lip GY, Cangemi R. Endotoxemia as a trigger of thrombosis in cirrhosis. Haematologica 2016;101:e162-e163. doi: 10.3324/haematol. 2015.139972.

[52] Dhiman RK, Behera A, Chawla YK, Dilawari JB, Suri S. Portal hypertensive biliopathy. Gut 2007;56:1001-1008. doi: 10.1136/gut.2006.103606.

[53] Khuroo MS, Yattoo GN, Zargar SA, Javid G, Dar MY, Khan BA, et al. Biliary abnormalities associated with extrahepatic portal venous obstruction. Hepatology 1993;17:807-813.

[54] Condat B, Vilgrain V, Asselah T, O'Toole D, Rufat P, Zappa M, et al. Portal cavernoma-associated cholangiopathy: a clinical and MR cholangiography coupled with MR portography imaging study. Hepatology 2003;37:13021308. doi: 10.1053/jhep.2003.50232.

[55] Luca A, Caruso S, Milazzo M, Marrone G, Mamone G, Crinò F, et al. Natural course of extrahepatic nonmalignant partial portal vein thrombosis in patients with cirrhosis. Radiology 2012;265:124-132. doi: 10 . 1148 /radiol.12112236.

[56] Girleanu I, Stanciu C, Cojocariu C, Boiculese L, Singeap AM, Trifan A. Natural course of nonmalignant partial portal vein thrombosis in cirrhotic patients. Saudi J Gastroenterol 2014;20:288-292. doi: 10.4103/13193767.141687.

[57] Chen H, Liu L, Qi X, He C, Wu F, Fan D, et al. Efficacy and safety of anticoagulation in more advanced portal vein thrombosis in patients with liver cirrhosis. Eur J Gastroenterol Hepatol 2016;28:82-89. doi: 10.1097/MEG. 0000000000000482.

[58] Wanless IR, Wong F, Blendis LM, Greig P, Heathcote EJ, Levy G. Hepatic and portal vein thrombosis in cirrhosis: possible role in development of parenchymal extinction and portal hypertension. Hepatology 1995;21:12381247.

[59] Villa E, Cammà C, Marietta M, Luongo M, Critelli R, Colopi S, et al. Enoxaparin prevents portal vein thrombosis and liver decompensation in patients with advanced cirrhosis. Gastroenterology 2012;143:1253-1260.e4. doi: $10.1053 /$ j.gastro.2012.07.018.

[60] D'Amico G, De Franchis R. Upper digestive bleeding in cirrhosis. Post-therapeutic outcome and prognostic indicators. Hepatology 2003;38:599-612. doi: $10.1053 /$ jhep.2003.50385.

[61] Dell'Era A, Iannuzzi F, Fabris FM, Fontana P, Reati R, Grillo P, et al. Impact of portal vein thrombosis on the efficacy of endoscopic variceal band ligation. Dig Liver Dis 2014;46:152-156. doi: 10.1016/j.dld.2013.08.138.

[62] Oi X, Dai J, Yang M, Ren W, Jia J, Guo X. Association between portal vein thrombosis and survival in non-liver-transplant patients with liver cirrhosis: A systematic review of the literature. Gastroenterol Res Pract 2015;2015: 480842. doi: $10.1155 / 2015 / 480842$.

[63] Lendoire J, Raffin G, Cejas N, Duek F, Barros Schelotto P, et al. Liver transplantation in adult patients with portal vein thrombosis: risk factors, management and outcome. HPB (Oxford) 2007;9:352-356. doi: 10. 1080/13651820701599033.

[64] Qi X, Dai J, Jia J, Ren W, Yang M, Li H, et al. Association between portal vein thrombosis and survival of liver transplant recipients: a systematic review and meta-analysis of observational studies. J Gastrointestin Liver Dis 2015 24:51-59. doi: 10.15403/jgld.2014.1121.qix.

[65] Hibi T, Nishida S, Levi DM, Selvaggi G, Tekin A, Fan J, et al. When and why portal vein thrombosis matters in liver transplantation: a critical audit of 174 cases. Ann Surg 2014;259:760-766. doi: 10.1097/SLA. 0000000000000252 . 
[66] Selvaggi G, Weppler D, Nishida S, Moon J, Levi D, Kato T, et al. Ten-year experience in porto-caval hemitransposition for liver transplantation in the presence of portal vein thrombosis. Am J Transplant 2007;7:454-460. doi: 10.1111/j.1600-6143.2006.01649.x.

[67] Montenovo M, Rahnemai-Azar A, Reyes J, Perkins J. Clinical impact and risk factors of portal vein thrombosis for patients on wait list for liver transplant. Exp Clin Transplant 2018;16:166-171. doi: 10.6002/ect.2016.0277.

[68] Tessler FN, Gehring BJ, Gomes AS, Perrella RR, Ragavendra N, Busuttil RW, et al. Diagnosis of portal vein thrombosis: value of color Doppler imaging. AJR Am J Roentgenol 1991;157:293-296. doi: 10.2214/ajr.157.2. 1853809.

[69] Bach AM, Hann LE, Brown KT, Getrajdman GI, Herman SK, Fong Y, et al. Portal vein evaluation with US: comparison to angiography combined with CT arterial portography. Radiology 1996;201:149-154. doi: 10.1148/radiology.201.1.8816536.

[70] Loudin M, Ahn J. Portal vein thrombosis in cirrhosis. J Clin Gastroenterol 2017;51:579-585. doi: 10.1097/MCG.0000000000000834.

[71] Hidajat N, Stobbe H, Griesshaber V, Felix R, Schroder RJ. Imaging and radiological interventions of portal vein thrombosis. Acta Radiol 2005;46: 336-343. doi: 10.1080/02841850510021157.

[72] Plessier A, Rautou PE, Valla DC. Management of hepatic vascular diseases. J Hepatol 2012;56 Suppl 1:S25-S38. doi: 10.1016/S0168-8278(12)60004$X$.

[73] Mantaka A, Augoustaki A, Kouroumalis EA, Samonakis DN. Portal vein thrombosis in cirrhosis: diagnosis, natural history, and therapeutic challenges. Ann Gastroenterol 2018;31:315-329. doi: 10.20524/aog.2018. 0245 .

[74] Shah TU, Semelka RC, Voultsinos V, Elias J Jr, Altun E, Pamuklar E, et al. Accuracy of magnetic resonance imaging for preoperative detection of portal vein thrombosis in liver transplant candidates. Liver Transpl 2006; 12:1682-1688. doi: 10.1002/It.20873.

[75] Kreft B, Strunk H, Flacke S, Wolff M, Conrad R, Gieseke J, et al. Detection of thrombosis in the portal venous system: comparison of contrast-enhanced MR angiography with intraarterial digital subtraction angiography. Radiology 2000;216:86-92. doi: 10.1148/radiology.216.1.r00j12386.

[76] Ravaioli M, Zanello M, Grazi GL, Ercolani G, Cescon M, Del Gaudio M, et al. Portal vein thrombosis and liver transplantation: evolution during 10 years of experience at the University of Bologna. Ann Surg 2011;253:378-384. doi: 10.1097/SLA.0b013e318206818b.

[77] Piscaglia F, Gianstefani A, Ravaioli M, Golfieri R, Cappelli A, Giampalma E, et al. Criteria for diagnosing benign portal vein thrombosis in the assessment of patients with cirrhosis and hepatocellular carcinoma for liver transplantation. Liver Transpl 2010;16:658-667. doi: 10.1002/lt.22044.

[78] Tublin ME, Dodd GD 3rd, Baron RL. Benign and malignant portal vein thrombosis: differentiation by CT characteristics. AJR Am J Roentgenol 1997;168: 719-723. doi: 10.2214/ajr.168.3.9057522.

[79] Delgado MG, Seijo S, Yepes I, Achécar L, Catalina MV, García-Criado A, et al. Efficacy and safety of anticoagulation on patients with cirrhosis and portal vein thrombosis. Clin Gastroenterol Hepatol 2012;10:776-783. doi: 10. 1016/j.cgh.2012.01.012.

[80] La Mura V, Braham S, Tosetti G, Branchi F, Bitto N, Moia M, et al. Harmful and beneficial effects of anticoagulants in patients with cirrhosis and portal vein thrombosis. Clin Gastroenterol Hepatol 2018;16:1146-1152.e4. doi: 10. 1016/j.cgh.2017.10.016.

[81] Werner KT, Sando S, Carey EJ, Vargas HE, Byrne TJ, Douglas DD, et al. Portal vein thrombosis in patients with end stage liver disease awaiting liver transplantation: outcome of anticoagulation. Dig Dis Sci 2013;58: 1776-1780. doi: 10.1007/s10620-012-2548-y.

[82] Noronha Ferreira C, Reis D, Cortez-Pinto H, Tato Marinho R, Gonçalves A, Palma $S$, et al. Anticoagulation in cirrhosis and portal vein thrombosis is safe and improves prognosis in advanced cirrhosis. Dig Dis Sci 2019;64:26712683. doi: $10.1007 / \mathrm{s} 10620-019-05572-z$

[83] Senzolo M, Sartori TM, Rossetto V, Burra P, Cillo U, Boccagni P, et al. Prospective evaluation of anticoagulation and transjugular intrahepatic portosystemic shunt for the management of portal vein thrombosis in cirrhosis. Liver Int 2012;32:919-927. doi: 10.1111/j.1478-3231.2012.02785.x.

[84] Amitrano L, Guardascione MA, Menchise A, Martino R, Scaglione M, Giovine $\mathrm{S}$, et al. Safety and efficacy of anticoagulation therapy with low molecular weight heparin for portal vein thrombosis in patients with liver cirrhosis. J Clin Gastroenterol 2010;44:448-451. doi: 10.1097/MCG. Ob013e3181b3ab44.

[85] Hanafy AS, Abd-Elsalam S, Dawoud MM. Randomized controlled trial of rivaroxaban versus warfarin in the management of acute non-neoplastic portal vein thrombosis. Vascul Pharmacol 2019;113:86-91. doi: 10. 1016/j.vph.2018.05.002.

[86] Nagaoki Y, Aikata H, Daijyo K, Teraoka Y, Shinohara F, Nakamura Y, et al. Efficacy and safety of edoxaban for treatment of portal vein thrombosis following danaparoid sodium in patients with liver cirrhosis. Hepatol Res 2018;48:51-58. doi: 10.1111/hepr.12895.
[87] De Gottardi A, Trebicka J, Klinger C, Plessier A, Seijo S, Terziroli B, et al. Antithrombotic treatment with direct-acting oral anticoagulants in patients with splanchnic vein thrombosis and cirrhosis. Liver Int 2017;37:694-699. doi: 10.1111/liv.13285.

[88] Faccia M, Ainora ME, Ponziani FR, Riccardi L, Garcovich M, Gasbarrini A, et al. Portal vein thrombosis in cirrhosis: Why a well-known complication is still matter of debate. World J Gastroenterol 2019;25:4437-4451. doi: 10.3748/wjg.v25.i31.4437.

[89] Rodrigues SG, Sixt S, Abraldes JG, De Gottardi A, Klinger C, Bosch J, et al. Systematic review with meta-analysis: portal vein recanalisation and transjugular intrahepatic portosystemic shunt for portal vein thrombosis. Aliment Pharmacol Ther 2019;49:20-30. doi: 10.1111/apt.15044.

[90] Salem R, Vouche M, Baker T, Herrero JI, Caicedo JC, Fryer J, et al. Pretransplant portal vein recanalization-transjugular intrahepatic portosystemic shunt in patients with complete obliterative portal vein thrombosis. Transplantation 2015;99:2347-2355. doi: 10.1097/TP.0000000000000729.

[91] Luca A, Miraglia R, Caruso S, Milazzo M, Sapere C, Maruzzelli L, et al. Shortand long-term effects of the transjugular intrahepatic portosystemic shunt on portal vein thrombosis in patients with cirrhosis. Gut 2011;60:846-852. doi: 10.1136/gut.2010.228023.

[92] Han G, Qi X, He C, Yin Z, Wang J, Xia J, et al. Transjugular intrahepatic portosystemic shunt for portal vein thrombosis with symptomatic portal hypertension in liver cirrhosis. J Hepatol 2011;54:78-88. doi: 10.1016/j. jhep.2010.06.029.

[93] Thornburg B, Desai K, Hickey R, Hohlastos E, Kulik L, Ganger D, et al. Pretransplantation portal vein recanalization and transjugular intrahepatic portosystemic shunt creation for chronic portal vein thrombosis: Final analysis of a 61-patient cohort. J Vasc Interv Radiol 2017;28:1714-1721.e2. doi: 10.1016/j.jvir.2017.08.005.

[94] Cui SB, Shu RH, Yan SP, Wu H, Chen Y, Wang L, et al. Efficacy and safety of anticoagulation therapy with different doses of enoxaparin for portal vein thrombosis in cirrhotic patients with hepatitis B. Eur J Gastroenterol Hepatol 2015;27:914-919. doi: 10.1097/MEG.0000000000000351.

[95] Kwon J, Koh Y, Yu SJ, Yoon JH. Low-molecular-weight heparin treatment for portal vein thrombosis in liver cirrhosis: Efficacy and the risk of hemorrhagic complications. Thromb Res 2018;163:71-76. doi: 10.1016/j.thromres. 2018.01.032

[96] Scheiner B, Stammet PR, Pokorny S, Bucsics T, Schwabl P, Brichta A, et al. Anticoagulation in non-malignant portal vein thrombosis is safe and improves hepatic function. Wien Klin Wochenschr 2018;130:446-455. doi: 10.1007/s00508-018-1351-y.

[97] Janczak DT, Mimier MK, McBane RD, Kamath PS, Simmons BS, Bott-Kitslaar DM, et al. Rivaroxaban and apixaban for initial treatment of acute venous thromboembolism of atypical location. Mayo Clin Proc 2018;93:40-47. doi: 10.1016/j.mayocp.2017.10.007.

[98] Loffredo L, Pastori D, Farcomeni A, Violi F. Effects of anticoagulants in patients with cirrhosis and portal vein thrombosis: A systematic review and meta-analysis. Gastroenterology 2017;153:480-487.e1. doi: 10. 1053/j.gastro.2017.04.042.

[99] Qi X, De Stefano V, Li H, Dai J, Guo X, Fan D. Anticoagulation for the treatment of portal vein thrombosis in liver cirrhosis: a systematic review and meta-analysis of observational studies. Eur J Intern Med 2015;26:23-29. doi: 10.1016/j.ejim.2014.12.002.

[100] Kubitza D, Roth A, Becka M, Alatrach A, Halabi A, Hinrichsen H, et al. Effect of hepatic impairment on the pharmacokinetics and pharmacodynamics of a single dose of rivaroxaban, an oral, direct Factor Xa inhibitor. $\mathrm{Br} \mathrm{J}$ Clin Pharmacol 2013;76:89-98. doi: 10.1111/bcp.12054.

[101] Graff J, Harder S. Anticoagulant therapy with the oral direct factor Xa inhibitors rivaroxaban, apixaban and edoxaban and the thrombin inhibitor dabigatran etexilate in patients with hepatic impairment. Clin Pharmacokinet 2013;52:243-254. doi: 10.1007/s40262-013-0034-0.

[102] Raschi E, Poluzzi E, Koci A, Salvo F, Pariente A, Biselli M, et al. Liver injury with novel oral anticoagulants: assessing post-marketing reports in the US Food and Drug Administration adverse event reporting system. Br J Clin Pharmacol 2015;80:285-293. doi: 10.1111/bcp.12611.

[103] Riggio O, Ridola L, Lucidi C, Angeloni S. Emerging issues in the use of transjugular intrahepatic portosystemic shunt (TIPS) for management of portal hypertension: time to update the guidelines? Dig Liver Dis 2010;42:462467. doi: 10.1016/j.dld.2009.11.007.

[104] Salerno F, Cammà C, Enea M, Rössle M, Wong F. Transjugular intrahepatic portosystemic shunt for refractory ascites: a meta-analysis of individual patient data. Gastroenterology 2007;133:825-834. doi: $10.1053 / \mathrm{j}$. gastro.2007.06.020.

[105] Bureau C, Thabut D, Oberti F, Dharancy S, Carbonell N, Bouvier A, et al. Transjugular intrahepatic portosystemic shunts with covered stents increase transplant-free survival of patients with cirrhosis and recurrent ascites. Gastroenterology 2017;152:157-163. doi: 10.1053/j.gastro. 2016.09.016. 
[106] García-Pagán JC, Caca K, Bureau C, Laleman W, Appenrodt B, Luca A, et al. Early use of TIPS in patients with cirrhosis and variceal bleeding. $N$ Engl $J$ Med 2010;362:2370-2379. doi: 10.1056/NEJMoa0910102.

[107] Shaw BW Jr, Iwatsuki S, Bron K, Starzl TE. Portal vein grafts in hepatic transplantation. Surg Gynecol Obstet 1985;161:66-68.

[108] Bhangui P, Lim C, Levesque E, Salloum C, Lahat E, Feray C, et al. Novel classification of non-malignant portal vein thrombosis: A guide to surgical decision-making during liver transplantation. J Hepatol 2019;71:10381050. doi: 10.1016/j.jhep.2019.08.012.

[109] Zanetto A, Rodriguez-Kastro KI, Germani G, Ferrarese A, Cillo U, Burra P, et al. Mortality in liver transplant recipients with portal vein thrombosis - an updated meta-analysis. Transpl Int 2018;31:1318-1329. doi: 10.1111/tri. 13353.
[110] Vianna RM, Mangus RS, Kubal C, Fridell JA, Beduschi T, Tector AJ. Multivisceral transplantation for diffuse portomesenteric thrombosis. Ann Surg 2012;255:1144-1150. doi: 10.1097/SLA.0b013e31825429c0.

[111] Kaltenborn A, Hartmann C, Salinas R, Ramackers W, Kleine M, Vondran FW, et al. Risk factors for short- and long-term mortality in liver transplant recipients with MELD score $\geq 30$. Ann Transplant 2015;20:59-69. doi: 10 . 12659/AOT.892322.

[112] Bhangui P, Fernandes ESM, Di Benedetto F, Joo DJ, Nadalin S. Current management of portal vein thrombosis in liver transplantation. Int J Surg 2020; 82S:122-127. doi: $10.1016 /$ j.ijsu.2020.04.068.

[113] Sharshar M, Yagi S, Iida T, Yao S, Miyachi Y, Macshut M, et al. Liver transplantation in patients with portal vein thrombosis: A strategic road map throughout management. Surgery 2020. doi: 10.1016/j.surg.2020.07.023. 